\title{
Correlation Between Tissue Densities in Com- puted Tomography and Three Different Cone- Beam Computed Tomography Units (In Vitro)
}

\section{S Mehralizadeh * ${ }^{1}$,A Talaipour ${ }^{2}$, P Olyaee $^{3}$, M Amiri Siavoshani $^{1}$}

1- Assistant professor,Oral and maxilofacial Radiology Dept ,Faculty of Dentistry,Tehran medical sciences,Islamic Azad University, Tehran, Iran

2- Professor,Oral and maxilofacial Radiology Dept, Tehran Medical Sciences, Islamic Azad University, Tehran, Iran, Islamic Azad University, Tehran, Iran

3- Dentist, Frankfurt, Germany

ARTICLE INFO

Article History

Received: Nov 2019

Accepted: Dec 2019

ePublished: Feb 2020

Corresponding author:

S Mehralizadeh,Assistant professor,Oral and maxilofacial Radiology Dept, faculty of Dentistry, Tehran medical sciences,Islamic Azad University, Tehran, Iran. Email: sandramehr@ yahoo.com

\begin{abstract}
Background and Aim: Bone density is of great assistance in the selection of the proper implant site. The present study aimed to assess the correlation between tissue densities in computed tomography (CT) and three different cone-beam computed tomography (CBCT) units.

Materials and Methods: In this descriptive study, a radiographic phantom consisting of a transparent polymethyl methacrylate (PMMA) cylinder with a 50-mm height and a 50-mm diameter was used, which comprised eight materials, including air, fat, water, PMMA, muscle, cortical bone, cancellous bone, and aluminum. Each material was of $5 \mathrm{~mm}$ height and $5 \mathrm{~mm}$ in diameter. A 20-mm-thick hollow plexiglass cylinder was used to simulate the soft tissue. The phantom was scanned four times using 16-Slice Lightspeed CT, NewTom VGi, CRANEX 3D, and Rotograph Evo 3D CBCT units. The data were primarily reconstructed and transferred to the OnDemand 3D software in the Digital Imaging and Communications in Medicine (DICOM) format. All the assessments were made in the sagittal plane, and the average density of each of the mentioned eight materials was calculated with the proper grayscale value calculation of each system, which utilizes a simulation inherent density calculation for any region of interest $(\mathrm{ROI})$.

Result: The results showed that tissue densities are different in CT and CBCT units. The values estimated by the CRANEX 3D unit approximated that of CT, followed by NewTom VGi and Rotograph Evo 3D CBCT units. Kruskal-Wallis test showed that the differences in the scores are statistically significant $(\mathrm{P}<0.01)$,

Conclusion:Considering the results, $\mathrm{CBCT}$ cannot accurately calculate tissue density. Keywords: Bone Density, Cone-Beam Computed Tomography, In Vitro Techniques, Multidetector Computed Tomography, Radiographic Image Interpretation, Computer-Assisted, Software
\end{abstract}

J Res Dent maxillofac Sci 2020, 5(1):13-20.

\section{Introduction:}

Assessment of the mechanical properties of the implant recipient bone is one of the concerns among dentists, which can significantly affect the osseointegration process and the primary stability of the implant..$^{(1-3)}$ and by $80 \%$ in developing countries by $2025 .^{(2)}$ One of the most important assessment indices is bone density, which is of great assistance in the selection of the proper- implant site. ${ }^{(4)}$ Armstrong, in 2006, stated that the Hounsfield Unit (HU) and the grayscale of a single point are not equal. ${ }^{(5)}$ Katsumata et al declared that grayscale values obtained by the use of cone-beam computed tomography (CBCT) are reliable. ${ }^{(6)}$ Mah et al stated that the differences between grayscale and HU are insignificant. (7) 
During recent years, computed tomography (CT) has been implemented in the assessment of bone quality. ${ }^{(4,6,7)}$ However, CT scan has some disadvantages including limited availability and a high effective dose. ${ }^{(4-8)}$ On the other hand, CBCT has many advantages such as a lower radiation dose, availability, shorter image acquisition time, and sub-millimeter resolution compared to CT. ${ }^{(9-12)}$ However, recent studies have proven that CBCT's effective dose is variable and can be affected by factors such as device type, the field of view (FOV), the number of base projections, and scan mode. ${ }^{(13)}$ Nevertheless, CBCT is the modality of choice for bone assessment before implant placement with approved accuracy of linear measurements and accurate assessment of adjacent anatomy. ${ }^{(14)}$ But disadvantages such as beam hardening artifact, high radiation scatter, and inability to render actual $\mathrm{HU}$ values are among the limitations of CBCT. ${ }^{(9,10,15,16)}$ CBCT has the potential to assess bone density, and overall, grayscale can be used for bone density assessment. ${ }^{(17-19)}$ However, the bone density obtained by the grayscale in CBCT has not yet been calibrated to conform to $\mathrm{HU}$ in $\mathrm{CT}$; their correlation is indefinite. ${ }^{(20)}$ The present in-vitro study aimed to assess the correlation between tissue densities in CT and three different CBCT units at the Oral and Maxillofacial Radiology Department of the Dental Faculty of Islamic Azad University of Medical Sciences, Tehran, Iran, during 2014-2015.

\section{Materials and Methods}

In this experimental study, a radiographic phantom comprised of eight materials, including air, fat, water, polymethyl methacrylate (PMMA), muscle, cortical bone, cancellous bone, and aluminum, was used. ${ }^{(7,11)}$ This phantom consisted of a transparent PMMA cylinder with a $50-\mathrm{mm}$ height and a $50-\mathrm{mm}$ diameter. ${ }^{(7)}$ The materials were located at the center of the phantom's vertical dimension in the following order: air, fat, water, PMMA, muscle, cancellous bone, cortical bone, and aluminum. Each material had a $5-\mathrm{mm}$ height and a 5-mm diameter. An empty cavity with a $5-\mathrm{mm}$ height and a $20-\mathrm{mm}$ diameter was

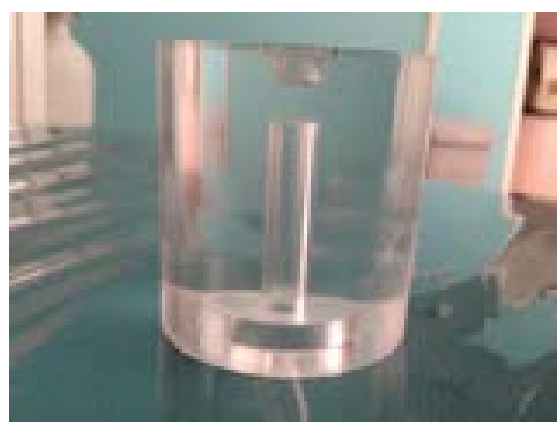

Figure 1. The phantom

A 20-mm-thick hollow plexiglass cylinder was used to simulate the soft tissue, and the samples were placed at the center of this cylinder (Figure 2). ${ }^{(21)}$

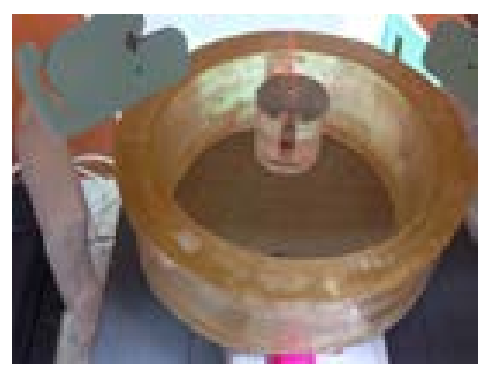

Figure 2. A 20-mm-thick hollow plexiglass cylinder was used to simulate the soft tissue

The CT unit in the present study was 16-slice Lightspeed CT (GE Medical Systems, USA). The CBCT units were NewTom VGi (Verona, Italy; CBCT1), CRANEX 3D (Soredex, Helsinki, Finland; CBCT2), and Rotograph Evo 3D (Villa, Italy; CBCT3). The phantom was placed at the center of the FOV, and scout images were obtained to ensure proper adjustment (Figure 3 ). ${ }^{(7)}$

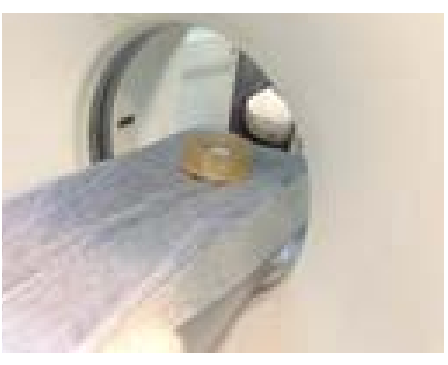

Figure 3. The phantom was placed at the center of the field of view (FOV), and scout images were obtained to ensure proper adjustment 
The obtained data were primarily reconstructed by the software provided by the manufacturing company of each scanner and were transferred in the Digital Imaging and Communications in Medicine (DICOM) format to third-party software for analysis. ${ }^{(7)}$ Softwares for primary reconstruction included: ADM software for 16-slice Lightspeed CT, NNT software for CBCT1, OnDemand Software for CBCT2, and Dental Studio Plus software for CBCT3.

The DICOM data analysis was performed by the OnDemand software (CyberMed International, Seoul, Korea) in the three-dimensional (3D) mode. ${ }^{(7)}$ All the assessments were made in the sagittal plane, and the average density of each of the mentioned eight materials was calculated. The grayscale value calculation of each system was performed with the utilization of a simulation of inherent density calculation for any region of interest (ROI). The images of each scan were captured by the image capture function of the OnDemand 3D software and were saved using the Microsoft Word Document software (Figure 4). ${ }^{(7)}$

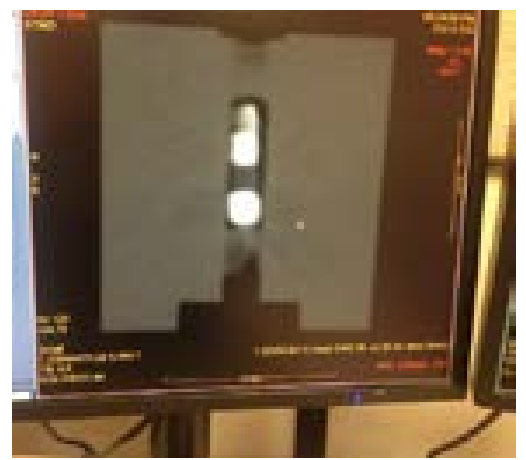

Figure 4. The images of each scan were captured by the image capture function of the OnDemand 3D software (CyberMed Inter(national, Seoul, Korea

The specifications of the scanner units employed in the present study are summa.rized in Table 1

To assess the correlation between HU and grayscale in the studied materials, the air was excluded from the study, and the sev.en remaining materials were compared

Table 1: The specifications of the scanner units employed in the present study

\begin{tabular}{|c|c|c|c|c|c|c|c|}
\hline Scanner & $\mathrm{kVp}$ & $\mathrm{mA}$ & $\begin{array}{c}\text { Scan } \\
\text { duration } \\
\text { (second) }\end{array}$ & FOV & $\begin{array}{l}\text { Voxel } \\
\text { size }\end{array}$ & $\begin{array}{l}\text { Scan } \\
\text { mode }\end{array}$ & Sensor type \\
\hline $\begin{array}{c}\text { 16-Slice } \\
\text { Lightspeed } \\
\text { CT }\end{array}$ & 120 & 300 & $0.5-4$ & Variable & -------- & $\begin{array}{l}\text { High } \\
\text { resolution }\end{array}$ & $\begin{array}{c}\text { Multi- } \\
\text { detector CT }\end{array}$ \\
\hline $\begin{array}{c}\text { NewTom } \\
\text { VGi CBCT }\end{array}$ & 110 & $1-20$ & $18-26$ & $120 \times 80 \mathrm{~mm}$ & $\begin{array}{c}300- \\
150 \mu \mathrm{m}\end{array}$ & $\begin{array}{l}\text { High } \\
\text { resolution }\end{array}$ & $\begin{array}{l}\text { Flat panel } \\
25 \times 25 \mathrm{~cm}\end{array}$ \\
\hline CRANEX 3D & 90 & $4-12$ & 12.6 & $100 \times 8 \mathrm{~mm}$ & $200 \mu \mathrm{m}$ & $\begin{array}{l}\text { High } \\
\text { resolution }\end{array}$ & $\begin{array}{l}\text { Flat panel } \\
61 \times 78 \mathrm{~mm}\end{array}$ \\
\hline $\begin{array}{l}\text { Rotograph } \\
\text { Evo 3D }\end{array}$ & $86 \pm 8 \%$ & $12 \pm 10 \%$ & 11.2 & $85 \times 85 \mathrm{~mm}$ & $166 \mu \mathrm{m}$ & $\begin{array}{l}\text { High } \\
\text { resolution }\end{array}$ & $\begin{array}{l}\text { Flat panel } \\
6 \times 22 \mathrm{~mm}\end{array}$ \\
\hline
\end{tabular}

$m A=$ milliampere, $k V p=$ kilovoltage peak, $F O V=$ field of view, $C T=$ computed tomography, $C B C T=$ cone-beam computed tomography 


\section{Results:}

The present study involved four scanner units, including one CT scan unit and three CBCT units (CBCT1, CBCT2, and CBCT3). Seven tissue samples were assessed. Therefore, the total number of 28 samples were evaluated. Tissue densities are presented in Table 2 .

Table 2: Densities of the assessed tissues according to the imaging modality

\begin{tabular}{lccccccc}
\hline Imaging modality & Aluminum & Cortical bone & Cancellous bone & PMMA & Water & Fat & Muscle \\
\hline 16-Slice Lightspeed CT & $3063 \pm 28$ & $1847 \pm 156$ & $660 \pm 156$ & $80.5 \pm 33$ & $30.1 \pm 28$ & $-70.6 \pm 26$ & $91.0 \pm 39$ \\
\hline Rotograph Evo 3D & $4831 \pm 103$ & $2765 \pm 71$ & $856 \pm 295$ & $-247 \pm 72$ & $-420 \pm 69$ & $-424 \pm 59$ & $-222 \pm 67$ \\
\hline NewTom VGi CBCT & $4768 \pm 60$ & $2827 \pm 18$ & $1327 \pm 233$ & $523 \pm 13$ & $273 \pm 15$ & $219 \pm 36$ & $531 \pm 15$ \\
\hline CRANEX 3D & $2996 \pm 90$ & $1881 \pm 16$ & $857 \pm 167$ & $363 \pm 33$ & $78.1 \pm 43$ & $173 \pm 55$ & $347 \pm 24$ \\
& & & & & & \\
\hline Test result & & & & & & & \\
\hline
\end{tabular}

$C T=$ computed tomography, $C B C T=$ cone-beam com-

puted tomography, PMMA=polymethyl methacrylate

\section{Aluminum}

The lowest density for aluminum was reported by CBCT2 (2996) followed by CT (3063) while the highest density was reported by CBCT3 (4831). Analysis of variance (ANOVA) showed that the differences among the four units were significant $(\mathrm{P}<0.001)$. Duncan's post hoc test showed no difference between $\mathrm{CT}$ and $\mathrm{CBCT} 2$ or between CBCT1 and CBCT3 $(\mathrm{P}<0.21)$ while $\mathrm{CT}$ and CBCT2 were significantly different from CBCT1 and $\mathrm{CBCT} 3(\mathrm{P}<0.01)$.

2. Cortical bone

The lowest density for this tissue was reported by CBCT2 (1881), and the highest density was reported by CBCT1 (2827; $\mathrm{P}<0.0001)$. Supplementary comparisons showed that $\mathrm{CT}$ was significantly different from the CBCT units $(\mathrm{P}<0.0001)$. CBCT1 and CBCT3 were not significantly different $(\mathrm{P}<0.2)$ while there were some differences among the three CBCT units $(\mathrm{P}<0.001)$.

3. Cancellous bone

The lowest density was reported by CT (660) while the densities reported by CBCT2 and
CBCT3 were almost equal (856). The highest density was reported by CBCT1 (1327) $(\mathrm{P}<0.001)$. Multiple comparisons showed that CT, CBCT2, and CBCT3 were not significantly different $(\mathrm{P}<0.6)$.

\section{PMMA}

The lowest density was reported by CBCT3 $(-247)$, and the highest density was reported by CBCT1 (523). Multiple comparisons showed a significant difference between the imaging units $(\mathrm{P}<0.001)$.

5. Water

Water density was -420 in CBCT3, 30 in CT, and 78 in CBCT1. The highest value was obtained by CBCT2 (273); the differences were statistically significant $(\mathrm{P}<0.01)$. There was a significant difference between $\mathrm{CT}$ and each of the CBCT units $(\mathrm{P}<0.001)$.

\section{Fat}

Fat density was -424 in CBCT3, -70 in CT, and 273 in CBCT2. The highest value was reported by CBCT1 (219); the difference was statistically significant $(\mathrm{P}<0.01)$. In other words, $\mathrm{CT}$ and 
CBCT3 rendered negative values while the values rendered by $\mathrm{CBCT} 1$ and 2 were not significantly different $(\mathrm{P}<0.4)$.

7. Muscle

CBCT3 showed the value of -222 , CT reported the value of 91, and CBCT1 showed the value of 347 while the highest density was reported by CBCT2 (531). The differences were statistically significant $(\mathrm{P}<0.0001)$. Pair comparisons by the post hoc test showed that these units were significantly different $(\mathrm{P}<0.0001)$.

Table 3 shows that the highest score (the closest value to CT) was related to CBCT2 (score 3) followed by CBCT1 (score 1.7) while the lowest score belonged to CBCT3 (1.28). Kruskal-Wallis test showed that these differences in the scores are statistically significant $(\mathrm{P}<0.01)$, and MannU-Whitney test, through pair comparisons of the CBCT units, showed a significant difference between $\mathrm{CBCT} 2$ with $\mathrm{CBCT} 1$ and $3(\mathrm{P}<0.05)$, but there was no difference between $\mathrm{CBCT} 1$ and CBCT3 $(\mathrm{P}<0.2)$.

Table 3-Score and quality ranking of each cone-beam computed tomography (CBCT) unit in comparison with computed tomography (CT)

\begin{tabular}{lllll}
\multirow{2}{*}{ CBCT } & \multirow{2}{*}{ Score } & Quality & \\
\cline { 3 - 5 } & & Excellent & Good & Moderate \\
\hline Rotograph Evo 3D(n=7) & $1.28 \pm 0.24$ & 0 & 2 & 5 \\
\hline NewTom VGi CBCT $(\mathrm{n}=7)$ & $1.71 \pm 0.49$ & 0 & 5 & 2 \\
\hline CRANEX 3D(n=7) & $3 \pm 0$ & 7 & 0 & 0 \\
\hline Test result & $\mathrm{P}<0.01$ & $\mathrm{P}<0.05$ & & \\
\hline
\end{tabular}

\footnotetext{
Discussion:

Assessment of bone quality and quantity is a fundamental step before implant placement surgeries. This assessment should be of adequate accuracy and validity. Although CBCT has been widely implemented in different dentistry fields, a reliable method for the assessment of bone quality by CBCT has not yet been recognized. ${ }^{(20)}$ Nowadays, CT is the gold standard for bone density estimations. ${ }^{(4,6,7)}$ Therefore, many studies have assessed the correlation between tissue densities in $\mathrm{CT}$ and $\mathrm{CBCT}$, and different results have been achieved. ${ }^{(17,18,20-35)}$
}

The present study showed that tissue densities are different in CT and CBCT units. CRANEX $3 \mathrm{D}$ showed the closest values to $\mathrm{CT}$ followed by NewTom VGi and Rotograph Evo 3D CBCT units.

A phantom comprised of seven materials with different densities was used in the present study. Mah et al used a standard phantom constructed under laboratory conditions in which each tissue was completely homogeneous. ${ }^{(7)}$ They declared an extremely strong correlation between CT HU and $\mathrm{CBCT}$ grayscale and rendered an equation for calculating HU based on CBCT grayscale. ${ }^{(7)}$ Lagravere et $\mathrm{al}^{(14)}$ identified the differences with the clinical conditions to be among the limitations of the study by Mah et al. ${ }^{(7)}$ Therefore, in the present study, natural tissues of a sheep's head were used.

Parsa et al declared a strong correlation between CBCT grayscale and CT HU; however, they emphasized that these two are not equal; they attributed the differences to the increased noise, scatter, and artifact in CBCT. ${ }^{(4)}$

Emadi et al stated that CBCT grayscale and CT HU are dissimilar and showed that the densities obtained by two different CBCT units are also dissimilar. ${ }^{(21)}$ However, the results of the present study showed a strong correlation between aluminum and cortical bone densities obtained by NewTom VGi and Rotograph Evo 3D CBCT units.

The thickness of the tissues is an important factor that can influence tissue density estimations. Therefore, in the present study, all the samples were of equal thickness. Although Katsumata et al stated that in thicker tissues, density estimation by CBCT is more accurate, they concluded that exposure parameters can have a greater effect on density assessment. ${ }^{(6)}$ They attributed the differences in tissue densities obtained by different units to the differences in the exposure parameters. ${ }^{(6)}$ Parsa et al also stated that changes in the exposure parameters could affect tissue density. ${ }^{(32)}$ In the present study, we tried to use comparable milliampere $(\mathrm{mA})$ and kilovoltage peak $(\mathrm{kVp})$ as permitted by the devices although some differences were inevitable. Haristoy et al hypothesized that the tissue density of an object is more influential in CT and 
CBCT compared to the projection intensity. ${ }^{(30)}$ In the present study, the phantom was placed at the center of the FOV. Lagravere et al found no significant differences between $\mathrm{CT} \mathrm{HU}$ and CBCT grayscale in different areas of the FOV ${ }^{(31)}$ while Oliveira et al found different results and stated that tissue density is influenced by the location of the tissue in the dental arch. ${ }^{(33)}$

The three CBCT units in this study operated in the high-resolution mode. Consequently, the signal-to-noise ratio (SNR) was increased, rendering high-quality images with a high spatial resolution, which can significantly affect tissue density measurements. ${ }^{(32)}$ De Vos et al showed that CBCT units lack similar adjustments and uniformity; these differences in manufacturing can affect the results of tissue density estimations with non-uniformity among different units. ${ }^{(35)}$ Therefore, we tried to select similar FOVs as possible but some differences were inevitable. Parsa et al showed that the size of the FOV could influence CBCT grayscale. ${ }^{(32)}$

We used a single software (the OnDemand 3D) for the observation and assessment of the scans of the three CBCT units to prevent the errors that could happen upon using multiple software. Mah et al implemented 11 CBCT units and a single software, similar to ours, to match the ROI in the samples. ${ }^{(7)}$

The results of the present study indicate that the densities obtained by the CBCT units show higher numbers than $\mathrm{CT}$ HU in similar tissues. The NewTom VGi CBCT unit showed higher densities for all the samples in comparison with the CT unit. Also, all the samples were shown to have higher densities in the CRANEX 3D CBCT unit compared to $\mathrm{CT}$ although the densities of aluminum and cortical bone showed close numbers to CT HU. In the Rotograph Evo 3D unit, the numbers were higher in comparison with CT HU, except for water, fat, and PMMA, which showed negative values. Scarfe et al found similar results. ${ }^{(29)}$ Although Lagravere et al found a linear correlation between $\mathrm{HU}$ and CBCT grayscale, they also found higher $\mathrm{CBCT}$ grayscale numbers compared to HU. (14) Generally, $\mathrm{kVp}$ and $\mathrm{mA}$ in CBCT are lower than that in CT, and consequently, CBCT has a higher SNR, which causes higher tissue density numbers compared to CT HU. (32) Haristoy and colleagues assessed the effect of different exposure parameters on grayscale and found a strong correlation between $\mathrm{HU}$ and CBCT grayscale. ${ }^{(30)}$ Due to the different results obtained from different CBCT units, they recommended the use of a calibrated phantom before imaging to ensure the accuracy of density estimations. ${ }^{(30)}$

It seems that although some studies have found a strong correlation between $\mathrm{HU}$ and CBCT grayscale, ${ }^{(4,7)}$ there is controversy among the results due to the differences in the study methods, statistical analyses, and scanner units. As stated recently by Pauwels et al, although many efforts have been made to determine accurate CBCT grayscale numbers, it is rational to consider these data unreliable. ${ }^{(36)}$ The limitations of CBCT units compared to medical CT units, which can be related to the characteristics of CBCT units, such as SNR, scatter radiation, and different artifacts, are most probably the main reason for this disagreement.

\section{Conclusion:}

Considering the results, $\mathrm{CBCT}$ cannot accurately calculate tissue density. It is recommended to assess the effect of factors such as tissue thickness, FOV size, location of the tissue in the FOV, and exposure parameters on tissue density calculations.

\section{References:}

1. Song YD, Jun SH, Kwon JJ. Correlation between bone quality evaluated by cone-beam computerized tomography and implant primary stability. Int J Oral Maxillofac Implants. 2009 Jan-Feb;24(1):59-64.

2. Isoda K, Ayukawa Y, Tsukiyama Y, Sogo M, Matsushita Y, Koyano K. Relationship between the bone density estimated by cone-beam computed tomography and the primary stability of dental implants. Clin Oral Implants Res. 2012 Jul;23(7):832-6.

3. Cassetta M, Stefanelli LV, Pacifici A, Pacifici $\mathrm{L}$, Barbato E. How accurate is CBCT in measuring bone density? A comparative CBCT-CT in vitro study. Clin Implant Dent Relat Res. 2014 Aug;16(4):471-8.

4. Parsa A, Ibrahim N, Hassan B, Motroni A, van der Stelt P, Wismeijer D. Reliability of voxel gray values in cone beam computed tomogra- 
phy for preoperative implant planning assessment. Int J Oral Maxillofac Implants. 2012 NovDec;27(6):1438-42.

5. Armstrong RT. Acceptability of cone beam CT vs. multi-detector CT for 3D anatomic model construction. J Oral Maxillofac Surg. 2006 Sep;64(9):37.

6. Katsumata A, Hirukawa A, Okumura S, Naitoh M, Fujishita M, Ariji E, et al. Relationship between density variability and imaging volume size in cone-beam computerized tomographic scanning of the maxillofacial region: an in vitro study. Oral Surg Oral Med Oral Pathol Oral Radiol Oral Endod. 2009 Mar;107(3):420-5.

7. Mah P, Reeves TE, McDavid WD. Deriving Hounsfield units using grey levels in cone beam computed tomography. Dentomaxillofac Radiol. 2010 Sep;39(6):323-35.

8. Cassetta M, Giansanti M, Di Mambro A, Calasso S, Barbato E. Accuracy of two stereolithographic surgical templates: a retrospective study. Clin Implant Dent Relat Res. 2013 Jun;15(3):44859.

9. Cassetta M, Stefanelli LV, Giansanti M, Di Mambro A, Calasso S. Depth deviation and occurrence of early surgical complications or unexpected events using a single stereolithographic surgi-guide. Int J Oral Maxillofac Surg. 2011 Dec;40(12):1377-87.

10. Scarfe WC, Farman AG. What is cone-beam $\mathrm{CT}$ and how does it work? Dent Clin North Am. 2008 Oct;52(4):707-30.

11. Razi T, Niknami M, Alavi Ghazani F. Relationship between Hounsfield Unit in CT scan and gray scale in CBCT. J Dent Res Dent Clin Dent Prospect. 2014 Spring;8(2):107-10.

12. Liu Y, Bäuerle T, Pan L, DimitrakopoulouStrauss A, Strauss LG, Heiss C, et al. Calibration of cone beam CT using relative attenuation ratio for quantitative assessment of bone density: a small animal study. Int J Comput Assist Radiol Surg. 2013 Sep;8(5):733-9.

13. Carrafiello G, Dizonno M, Colli V, Strocchi S, Taubert SP, Leonardi A, et al. Comparative study of jaws with multislice computed tomography and cone-beam computed tomography. Radiol Med. 2010 Jun;115(4):600-11.

14. Lagravere MO, Carey J, Toogood RW, Major PW. Three-dimensional accuracy of measurements made with software on cone-beam comput- ed tomography images. Am J Orthod Dentofacial Orthop. 2008 Jul;134(1):112-6.

15. Pauwels R, Beinsberger J, Collaert B, Theodorakou C, Rogers J, Walker A, et al. Effective dose range for dental cone beam computed tomography scanners. Eur J Radiol. 2012 Feb;81(2):267-71.

16. Hua Y, Nackaerts O, Duyck J, Maes F, Jacobs $\mathrm{R}$. Bone quality assessment based on cone beam computed tomography imaging. Clin Oral Implant Res. 2009 Aug;20(8):767-71.

17. Schulze R, Heil U, Gross D, Bruellmann DD, Dranischnikow E, Schwanecka U, et al. Artefacts in CBCT: a review. Dentomaxillofac Radiol. 2011 Jul:40(5);265-73.

18. Kim DG. Can dental cone beam computed tomography assess bone mineral density? J Bone Metab. 2014 May;21(2):117-26.

19. Naitoh M, Hirukawa A, Katsumata A, Ariji E. Prospective study to estimate mandibular cancellous bone density using large-volume cone-beam computed tomography. Clin Oral Implant Res. 2010 Dec;21(12):1309-13.

20. Gonzalez-Garica R, Monje F. The reliability of cone-beam computed tomography to assess bone density at dental implant recipient sites: a histomorphometric analysis by micro-CT. Clin Oral Implant Res. 2013 Aug;24(8):871-9.

21. Emadi N, Safi Y, Akbarzadeh Bagheban A, Asgary S. Comparison of CT-number and gray scale value of different dental materials and hard tissues in CT and CBCT. Iran Endod J. 2014 Fall;9(4):283-6.

22. Merrett SJ, Drage NA, Durning P. Cone beam computed tomography: a useful tool in orthodontic diagnosis and treatment planning. J Orthod. 2009 Sep;36(3):202-10.

23. Hofmann E, Medelnik J, Fink M, Lell M, Hischfelder U. Three-dimensional volume tomographic study of the imaging accuracy of impacted teeth: MSCT and CBCT comparison--an in vitro study. Eur J Orthod. 2013 Jun;35(3):286-94. 24. Litsas G, Acar A. A review of early displaced maxillary canines: etiology, diagnosis and interceptive treatment. Open Dent J. 2011 Mar 16;5:39-47.

25. Arisan V, Karabuda ZC, Avsever H, Özdemir T. Conventional multi-slice computed tomography (CT) and cone-beam CT (CBCT) for computer-assisted implant placement. Part I: re- 
lationship of radiographic gray density and implant stability. Clin Implant Dent Relat Res. 2013 Dec;15(6):893-906.

26. Naitoh M, Hirukawa A, Katsumata A, Ariji E. Evaluation of voxel values in mandibular cancellous bone: relationship between cone-beam computed tomography and multislice helical computed tomography. Clin Oral Implants Res. 2009 May;20(5):503-6.

27. Schropp L, Alyass NS, Wenzel A, Stavropoulos A. Validity of wax and acrylic as softtissue simulation materials used in in vitro radiographic studies. Dentomaxillofac Radiol. 2012 Dec;41(8):686-90.

28. Aranyarachkul P, Caruso J, Gantes B, Schulz E, Riggs M, Dus I, et al. Bone density assessments of dental implant sites: 2. Quantitative cone-beam computerized tomography. Int J Oral Maxillofac Implants. 2005 May-Jun;20(3):416-24.

29. Scarfe WC, Farman AG, Sukovic P. Clinical applications of cone-beam computed tomography in dental practice. J Can Dent Assoc. 2006 Feb;72(1):75-80.

30. Haristoy RA, Valiyaparambil JV, Mallya SM. Correlation of CBCT gray scale values with bone densities. Oral Surg Oral Med Oral Pathol Oral Radiol Endod. 2009;107(4):e28.

31. Lagravere MO, Carey J, Ben-Zvi M, Packota GV, Major PW. Effect of object location on the density measurement and Hounsfield conversion in a NewTom $3 \mathrm{G}$ cone beam computer tomography unit. Dentomaxillofac Radiol. 2008 Sep;37(6):305-8.

32. Parsa A. Ibrahim N, Hassan B, Motroni A, van der Stelt $\mathrm{P}$, Wismeijer D. Influence of cone beam CT scanning parameters on gray value measurements at an implant site. Dentomaxillofac Radiol. 2013 Mar;42(3):79884780.

33. Oliveira ML, Tosoni GM, Lindsey DH, Mendoza K, Tetradis S, Mallya SM. Influence of anatomical location on CT numbers in cone beam computed tomography. Oral Surg Oral Med Oral Pathol Oral Radiol. 2013 Apr;115(4):558-64.

34. Loubele M, Jacobs R, Maes F, Denis K, White S, Coudyzer W, et al. Image quality vs. radiation dose of four cone beam computed tomography scanners. Dentomaillofacial Radiol. 2008 Sep;37(6):309-18.

35. De Vos W, Casselman J. Swennen GR. Conebeam computerized tomography (CBCT) imag- ing of the oral and maxillofacial region: a systematic review of the literature. Int J Oral Maxillofac Surg. 2009 Jun;38(6);609-25.

36. Pauwels R, Jacobs R, Singer SR, Mupparapu M. CBCT-based bone quality assessment: are Hounsfield units applicable? Dentomaxillofac Radiol. 2015;44(1):20140238.

Please cite this paper as: Mehralizadeh S, Talaipour A, Olyaee P, Amiri siavoshani M. Correlation Between Tissue Densities in Computed Tomography and Three Different Cone-Beam Computed Tomography Units (In Vitro). J Res Dentomaxillofac Sci. 2020; 5 (1) : 13-20 